\title{
Quality Characteristics and Functional and Antioxidant Capacities of Algae-Fortified Fish Burgers Prepared from Common Barbel (Barbus barbus)
}

\author{
Faiez Hentati, ${ }^{1,2}$ Mohamed Barkallah, ${ }^{1}$ Ali Ben Atitallah, ${ }^{1}$ \\ Mouna Dammak, ${ }^{1}$ Ibtihel Louati, ${ }^{3}$ Guillaume Pierre, ${ }^{2}$ Imen Fendri, ${ }^{4}$ \\ Hamadi Attia, ${ }^{5}$ Philippe Michaud, ${ }^{2}$ and Slim Abdelkafi ${ }^{1}{ }^{1}$ \\ ${ }^{1}$ Unité de Biotechnologie des Algues, Biological Engineering Department, National Engineering School of Sfax, University of Sfax, \\ 3038 Sfax, Tunisia \\ ${ }^{2}$ Université Clermont Auvergne, CNRS, SIGMA Clermont, Institut Pascal, F-63000 Clermont-Ferrand, France \\ ${ }^{3}$ Laboratoire de Génie Enzymatique et de Microbiologie, University of Sfax, National Engineering School of Sfax, \\ B.P. 1173-3038 Sfax, Tunisia \\ ${ }^{4}$ Laboratory of Plant Biotechnology Applied to the Improvement of Cultures, Faculty of Sciences of Sfax, B.P. 1171, No. 3000, \\ University of Sfax, 3029 Sfax, Tunisia \\ ${ }^{5}$ Laboratory of Analysis Valorization and Food Safety, National Engineering School of Sfax, University of Sfax, 3038 Sfax, Tunisia
}

Correspondence should be addressed to Slim Abdelkafi; slim.abdelkafi@enis.tn

Received 8 April 2019; Revised 4 July 2019; Accepted 16 July 2019; Published 9 October 2019

Academic Editor: Vasiliki Galani

Copyright (C) 2019 Faiez Hentati et al. This is an open access article distributed under the Creative Commons Attribution License, which permits unrestricted use, distribution, and reproduction in any medium, provided the original work is properly cited.

\begin{abstract}
Introduction. Algae have been used as natural ingredients to produce new canned fish burgers prepared from minced flesh of common barbel. In this research, the impact of the addition of Cystoseira compressa and Jania adhaerens at concentrations of $0.5,1$, and $1.5 \% \mathrm{w} / \mathrm{v}$ on the texture and sensory characteristics of fish burgers were investigated. Results. Compared to controls, fish burgers containing $1 \%$ algae had better texture and sensory properties $(P<0.05)$. Also, these burger formulations had higher water and oil holding capacities as well as swelling ability, due to the important polysaccharides and dietary fibers contents of algae. In addition, algae-supplemented burgers were characterized as having low $\mathrm{L}^{*}, \mathrm{a}^{*}$, and $\mathrm{b}^{*}$ values, which made the color appear to be paler. Thanks to their high richness in pigments (chlorophylls and carotenoids) and polysaccharides, algae considerably enhance the antioxidant activities of the new ready-to-eat fish burgers. So, Cystoseira compressa and Jania adhaerens could be used as nutritious additives to produce new fish-based products.
\end{abstract}

\section{Background}

Fishing in Tunisia has mostly exploited the benthic stocks which are actually in optimal exploitation state or even overexploitation. This condition has incited the Tunisian authorities to search effective solutions such as the development of aquaculture and the recovery of untapped fish. As a result, the idea of exploiting freshwater fish species (Tilapia of the Nile, common carp (Cyprinus Carpio), and common barbel (Barbus barbus)) in intensive farming has emerged. The common barbel is a freshwater fish species that belongs to the Cyprinidae family and exists in many Tunisian dams thanks to its good adaptation to the environment. His flesh is rich in $\omega 3$-series polyunsaturated fatty acids with long chains such as eicosapentaenoic acid (EPA) and docosahexaenoic acid (DHA), fat-soluble vitamins (A, D, and especially E), water-soluble vitamins (B12 and especially B6) and low levels of cholesterol and saturated fats [1]. All these compounds are beneficial to people's health and they are necessary for the growth and protection of the human body [1]. The presence of intramuscular bones in the flesh of common barbel is the cause of its low consumption by the Tunisians. 
Hence, it is very substantial to create and produce new fishbased products from these underutilized fish species so as to enhance their consumer acceptability.

Despite their health benefits, fish-based products are not generally considered as a primary source of bioactive compounds (polysaccharides, pigments...) [2]. In the agroalimentary industries, various synthetic additives have been popularly used for the aims of coloring, fortifying, and extending the shelf-life of the marketed products $[3,4]$. Nevertheless, many recent studies have indicated that the unreasonable consumption of artificial additives is related to many health problems $[5,6]$. Thus, the need to use natural food fortifiers has pushed nutrition experts to generate supplements from natural resources that might be suitable for food products $[4,7]$.

Recently, the consumption of marine products such algae (C. compressa and J. adhaerens) has gradually increased for the gradual awareness of the close relationship between diet and health [8]. As a result, many food products containing algae have been marketed. Indeed, algae are an interesting source of natural antioxidants and antimicrobials agents which have been successfully used in some foods such as porcine [9], beef [10], chicken [11], fish and seafood [12, 13] products. They can turn food more functional with high added value and so, they can guarantee the consumer's satisfaction. To the best of our knowledge, studies regarding the use of algae in processed fish products are lacking.

In this respect, this study has two principal objectives. The first one is to produce new eatable fish burgers prepared from minced flesh of common barbel and fortified with algae (Cystoseira compressa and Jania adhaerens), which are rich in bioactive compounds (pigments and polysaccharides). The second one is to assess the beneficial effects of algae on the sensorial, textural, physicochemical, microbiological, functional, and antioxidant properties of these fish products.

\section{Materials and Methods}

2.1. Algae. In 2016, J. adhaerens and C. compressa were harvested from Tabarka (Governorate of Jendouba, Tunisia) and Kerkennah island (Governorate of Sfax, Tunisia), respectively. After cutting them, they were washed with fresh water, sun-dried at ambient temperature, milled, treated with a sieve of $0.2 \mathrm{~mm}$ mesh and stored in sealed bags under room temperature. The algae powders obtained were analyzed for their moisture, protein, ash and fat according to the AOAC official method (Method 993.21.) [14]. Total carbohydrate and uronic acid concentrations were evaluated after acid hydrolysis $\left(\mathrm{H}_{2} \mathrm{SO}_{4}(96 \%), 1 \mathrm{~h}, 30^{\circ} \mathrm{C}\right)$ by the phenol-sulfuric acid method [15] and m-hydroxydiphenyl (MHDP) assay [16], respectively. Functional and chemical composition, including water holding capacity, oil absorption capacity, total dietary fiber and pigments were determined using the same methods as described in the coming parts (Sections 2.5 and 2.6).

2.2. Fish Collection. Freshwater fish (common barbel, Barbus barbus) were sampled in January 2017 from the reservoir of Sidi Salem (Governorate of Beja) by professional fishermen, using gill nets of mesh size equal to $80 \mathrm{~mm}$. The fish were between 40 and $55 \mathrm{~cm}$ long and their weight ranged from 0.7 to $2.5 \mathrm{~kg}$. Next, they were stored in isotherm ice polyethylene boxes $\left(\sim 0^{\circ} \mathrm{C}\right)$ and $1 \mathrm{~h}$ after they were immediately transported to the pilot unit of fish processing of Tabarka in order to test their freshness. The samples were then washed, weighed, scaled, eviscerated and fileted so as to obtain clean fish fillets. After being cut into small pieces, the skinless fish filets were minced during 2-3 min in a blender (Robot Coupe USA Inc., Ridgeland, MS, USA) and kept at $-20^{\circ} \mathrm{C}$ for $48 \mathrm{~h}$.

2.3. Formulation and Production of Fish Burger. All the stages of the fish burgers processing were performed in the pilot fish processing unit of Tabarka (Jendouba, Tabarka, Tunisia) in collaboration with the Interprofessional Grouping of the Fishery Products (GIPP, Tunis, Tunisia). After being thawed overnight in the refrigerator, the minced meat was thoroughly mixed with salt $(2 \%, \mathrm{w} / \mathrm{w})$, cornstarch (Spipa, Tunis, Tunisia) $(1 \%, w / w)$ and with different concentrations $(0.5,1$ and $1.5 \%$, $\mathrm{w} / \mathrm{w}$ ) of algae (C. compressa and J. adhaerens) powders. A combination of $C$. compressa/J. adhaerens (proportions of $1 / 1$, w/w) was also tested depending to their preliminary results.

Then, the shaping of fish burgers was then carried out using a commercial burger maker (Hamburger MV NEW model, Food Tech Srl, Bologna, Italy) in order to get disc burger pieces which $6 \mathrm{~cm}$ wide and $1.5 \mathrm{~cm}$ thick and which weigh $100 \mathrm{~g}$. Algae-free burgers were used as controls. Burgers were separately placed in a well-washed and wiped metal tin can that was $8.54 \mathrm{~cm}$ wide and $3.7 \mathrm{~cm}$ high, immediately soaked in sunflower oil (Safi, Ben Arous, Tunisia) and then packaged by a crimping machine (Seamer Semiautomatica, MOD.AGM, S-Bologna, Italy) in order to ensure complete sealing. Finally, the cans were washed, for the purpose of removing the excess of oil, and sterilized in a retort at $120^{\circ} \mathrm{C}$ for $40 \mathrm{~min}$ [17]. They were stored in an alimentary refrigerator at $4^{\circ} \mathrm{C}$ for further analyses ( 8 months).

\subsection{Nutritional Properties of Algae Enriched Fish Burgers}

2.4.1. Dry Matter, Moisture and Ash Content. Dry matter (DM) and ash were determined according to AOAC [14] method. DM was determined by drying samples at $105^{\circ} \mathrm{C}$ for $24 \mathrm{~h}$ in an air oven (Thermoline Scientific, Australia). The mineral content was quantified after heating the samples at $550^{\circ} \mathrm{C}$ for $4 \mathrm{~h}$ in an electric muffle furnace (Labec Laboratory Pty Ltd., Marrickville, NSW, Australia). This was expressed as percentage of ash in DW.

2.4.2. Protein, Dietary Fiber and Lipid Content Analysis. The protein content was determined by the Kjeldhal assay according to AOAC International method [14] with a nitrogen conversion factor of 6.25 [18]. The total dietary fibers (TDF) were quantified by the nonenzymatic gravimetric method (AOAC Official Method 993.21.) based on the precipitation of fibers with ethanol [19]. The total lipids of burger were extracted and quantified according to the modified procedure of Bligh and Dyer [20] with chloroform, methanol, and water $(2 / 1 / 1, v / v)$. 


\subsection{Chemical Composition and Antioxidant Potential of Algae Enriched Fish Burger}

2.5.1. Chlorophylls and Carotenoids Contents. The carotenoid and chlorophylls contents were determined by spectrophotometry as described by Lichtenthaler and Wellburn [21] and Kumar et al. [22] after adding $2 \mathrm{~mL}$ of ethanol (96\%) to $0.2 \mathrm{~g}$ of samples and letting them incubate at $65^{\circ} \mathrm{C}$ for $30 \mathrm{~min}$ under a continuous stirring. After sonication ( $15 \mathrm{~min}, 60 \mathrm{~W}, 40$ $\mathrm{kHz}$ ) by using an ultrasonic bath (Bandelin Electronic, Berlin, Germany), the suspensions were centrifuged at $10,000 \mathrm{~g}$ for 5 $\min$ at $20^{\circ} \mathrm{C}$. The concentrations of pigments in supernatants were measured at 666,653 and $470 \mathrm{~nm}$ using the Equations (1), (2) and (3):

$$
\begin{aligned}
& {[\text { Chl a }](\mathrm{mg} / \mathrm{L})=15.65 \times A_{666}-7.340 \times A_{653}} \\
& {[\text { Chlb }](\mathrm{mg} / \mathrm{L})=27.05 \times A_{653}-11.21 \times A_{666}} \\
& {[\text { Carotenoids }](\mathrm{mg} / \mathrm{L})} \\
& \quad=\frac{\left(1000 \times A_{470}-2.86 \times[\text { Chl a }]-85.9 \times[\text { Chl b }]\right)}{245}
\end{aligned}
$$

2.5.2. FT-IR Spectroscopy. The absorption spectra of all burger formulations were obtained using Fourier Transform Infrared Spectroscopy (FTIR) (Agilent Technologies Spectrophotometer, Cory 630 FT-IR). For that, dried samples were deposited on accessory plate. The transmission spectra were obtained in the wave-number range of $600-4000 \mathrm{~cm}^{-1}$ at a resolution of $4 \mathrm{~cm}^{-1}$. For each sample, an average of 10 scans has been done. The acquisition and the processing of spectra have been carried out using the "Spectrum" software.

2.5.3. Evaluation of Antioxidant Properties. The antiradical activity was measured using the synthetic radical DPPH (1,1diphenyl-2-picrylhydrazyl) using the method of Bersuder et al. [23]. Approximately $10 \mathrm{mg}$ of the sample was suspended in $0.5 \mathrm{~mL}$ of distilled water. After making up to $1.2 \mathrm{~mL}$ with $0.5 \mathrm{~mL}$ of absolute ethanol and $0.2 \mathrm{~mL}$ of DPPH $(50 \mu \mathrm{M}$ in ethanol), the mixture was incubated for $30 \mathrm{~min}$ in the dark at room temperature. The absorbance was measured at $517 \mathrm{~nm}$ using the T70 UV-visible spectrophotometer (PG Instruments Ltd., Beijing, China). The control was done in the same manner, expect that distilled water was used instead of sample.

From the absorbance, \% inhibition or \% scavenging activity is calculated using the formula,

DPPH scavenging activity

$$
=\left(\frac{(\text { OD control }- \text { OD sample })}{\text { OD control }}\right) \times 100
$$

The ferric reducing antioxidant power (FRAP) of burger samples was determined using the method of Yildirim et al. [24]. Fish burgers were cut into small pieces $(10 \mathrm{mg})$, immersed in $0.1 \mathrm{~mL}$ of distilled water and mixed with $2.5 \mathrm{~mL}$ of sodium phosphate buffer $\left(\mathrm{NaHPO}_{4}, 0.2 \mathrm{M}, \mathrm{pH}\right.$ 6.6) and $2.5 \mathrm{~mL}$ of $1 \%(\mathrm{w} / \mathrm{v})$ potassium ferricyanide $\left(\mathrm{K}_{3} \mathrm{Fe}(\mathrm{CN})_{6}\right)$. The mixtures were incubated for $30 \mathrm{~min}$ at $50^{\circ} \mathrm{C}$. After incubation, $2.5 \mathrm{~mL}$ of $10 \%$ trichloroacetic acid (TCA) were added and the reaction mixtures were centrifuged at $10,000 \mathrm{~g}$ for $10 \mathrm{~min}$ at $4^{\circ} \mathrm{C}$. Finally, $2.5 \mathrm{~mL}$ of the upper layer solution was taken and mixed with $2.5 \mathrm{~mL}$ of distilled water and $0.5 \mathrm{~mL}$ of $0.1 \%$ ferric chloride. The procedure was carried out in triplicate and absorbance was measured at $700 \mathrm{~nm}$.

\subsection{Quality and Shelf-Life Measurements}

2.6.1. Physical Characteristics of Fish Burger. All the measurements were done during the first month after production and all measurements were carried out in triplicate. The $\mathrm{pH}$ was measured using a calibrated $\mathrm{pH}$ meter (Metrohm-744 pH meter, Heirisau Switzerland) equipped with a glass probe to ensure penetration into fish burger. The water activities $\left(\mathrm{a}_{\mathrm{w}}\right)$ of wet and dried products were determined using a calibrated SPRINT Novasina Thermoconstanter SPRINT TH500 (Axair Ltd., Pfäffikon, Switzerland) at $25^{\circ} \mathrm{C}$. The equipment was previously calibrated according to the calibration procedure of the equipment manufacturer using the following salts: $\mathrm{MgCl}_{2}, \mathrm{NaCl}, \mathrm{BaCl}_{2}$ and $\mathrm{K}_{2} \mathrm{Cr}_{2} \mathrm{O}_{7}$.

2.6.2. Functional Properties of Fish Burger. The swelling capacity of fish burgers (SWC) was determined as described by Wong and Cheung [25] with slight modifications. Dried samples $(200 \mathrm{mg})$ were placed in a $50 \mathrm{~mL}$ graduated glass cylinder. After making up the volume to $50 \mathrm{~mL}$ with distilled water, the mixtures were stirred for 2-3 min and then stored at ambient temperature for $24 \mathrm{~h}$. The swelling volume was measured and expressed in $\mathrm{mL}$ of swollen sample per grams of dry weight (DW) of burger.

The water holding capacity (WHC) was measured according to Okezie and Bello [26] method. Sample $(0.4 \mathrm{~g})$ was mixed with $40 \mathrm{~mL}$ of distilled water in centrifuged tubes and stirred for $24 \mathrm{~h}$ at room temperature. After centrifugation $\left(14,000 \mathrm{~g}, 4^{\circ} \mathrm{C}, 20 \mathrm{~min}\right)$, the supernatant was filtered through Whatman filter paper of porosity 1 (Whatman International Ltd., Maidstone, England) and the recovered volume (filtrate) was then measured. The difference between the initial volume and that of supernatant (WHC) was expressed as the weight of water held per gram of dry sample.

The oil holding capacity (OHC) was determined according to the method adapted from Wong and Cheung [25]. Three grams of dried fish burger were mixed with $8 \mathrm{~g}$ of corn oil (Safi, Ben Arous, Tunisia) and incubated at ambient temperature for a $30 \mathrm{~min}$ under continuous stirring. The mixture was then centrifuged at $2,500 \mathrm{~g}$ for $30 \mathrm{~min}$ at $20^{\circ} \mathrm{C}$. The oil supernatant was then recovered and measured. OHC of burgers was expressed as grams of absorbed oil per gram of sample. All measurements were carried out in triplicates.

2.6.3. Sensory Evaluation. The sensory evaluations of burgers were done according to the protocol proposed by Barkallah et al. [27] and Jridi et al. [28]. The attributes of burger samples were conducted by 32 panelists ( 22 female and 10 male) aged from 20 to 45 years, 7 days after the production of burgers. The tasting panel included agri-food engineers and biological researchers in the pilot unit of fish processing. Samples were 
distributed on polystyrene plates and presented to the panelists with three digit codes in a random order. Experiments were performed in a sensory evaluation room equipped with white light and controlled ventilation and water was served for perfectly cleaning the mouth between samples. Members of the sensory panel evaluated the fish burgers for taste, appearance, texture, color and odor based on a traditional 5 point-hedonic scale ranging from 1 (extremely disliked) to 5 (extremely liked) $(1=$ very bad, $2=$ bad, $3=$ neither bad nor good, $4=$ good and $5=$ very good) for each parameter [29]. A score of 4 was considered the threshold for acceptance of the fish burger.

2.6.4. Color Analysis. Color evaluation of canned burger was made using a spectro-colorimeter (Konica Minolta, Chroma Meter, CR400, Japan). An average color value was expressed by measuring five different points of the same sample. The CIE-Lab color scale was used to measure the lightness $\left(\mathrm{L}^{*}\right)$, redness $\left(+\mathrm{a}^{*}\right)$ or greenery $\left(-\mathrm{a}^{*}\right)$ and yellowing $\left(+b^{*}\right)$ or blue $\left(-b^{*}\right)$. The instrument was calibrated using standard white plates with color coordinates of $\mathrm{L}^{*}$ standard $=97.6, \mathrm{a}^{*}$ standard $=0.03$ and $\mathrm{b}^{*}$ standard $=1.73$, supplied by Minolta. The color can also be expressed in polar (or cylindrical) coordinates $\mathrm{L}^{*}, \mathrm{C}^{*}$ and $\mathrm{h}^{*}$, where $\mathrm{L}^{*}$ is identical to that described previously, $\mathrm{C}^{*}$ is the chroma or saturation index and $\mathrm{h}^{*}$ is the color tint of the product. The following Equations ((5) and (6)) were used to convert the coordinates $\mathrm{L}^{*} \mathrm{a}^{*} \mathrm{~b}^{*}$ into cylindrical coordinates $\mathrm{L}^{*} \mathrm{C}^{*} \mathrm{~h}^{*}$ :

$$
\begin{aligned}
& C^{*}=\left(a^{*^{2}}+b^{*^{2}}\right)^{0.5} \\
& h^{*}=\operatorname{arctang}\left(\frac{b^{*}}{a^{*}}\right)
\end{aligned}
$$

2.6.5. Textural Analysis. Texture analysis of fish burgers stored for at least $24 \mathrm{~h}$ at $4^{\circ} \mathrm{C}$ was performed using a texture analyzer (Texture Analyseur, TA Plus, Lloyd Instruments, Bognor Regis, UK) equipped with a 1000 (N) load cell and $0.05(\mathrm{~N})$ detection range [30]. The test was applied directly on burgers which were $4 \mathrm{~cm}$ long and $4 \mathrm{~cm}$ wide using a $12-\mathrm{mm}$ diameter analysis probe. The samples underwent a compression step of $50 \%$ of their original thickness in a double cycle with a rate of $40 \mathrm{~mm} / \mathrm{min}$. The pre-test speed and the target mode distance were set at $1.5 \mathrm{~mm} / \mathrm{s}$ and $10 \mathrm{~mm}$, respectively. The trigger force (trigger type: auto) was fixed at $5 \mathrm{~g}$ and the data acquisition rate was programmed at 200 points/s. The texture profile parameters such as cohesiveness, elasticity $(\mathrm{mm})$ and firmness $(\mathrm{N})$ were calculated from the resulting force-strain curves.

2.6.6. Microbiological Analysis. The microbiological analyses of fish burger were examined throughout the storage period $[31,32]$. The tests of Escherichia coli, Enterobacteriaceae, yeast, mold, coliforms and foodborne pathogens (Salmonella spp., Shigella spp., Bacillus cereus, Listeria monocytogenes, and Staphylococcus aureus) were performed using the standard microbiological methods for the analysis of ready-to-eat foods [33]. After enrichment, burger samples were plated onto polymyxin - acriflavine - lithium chloride - ceftazidime - aesculin - mannitol (PALCAM) agar (Conda, Madrid, Spain), Baird Parker agar (Oxoid Ltd., Hampshire, UK) and Salmonella-Shigella (SS) agar (Conda, Madrid, Spain) for the detection of L. monocytogenes, S. aureus and SalmonellaShigella, respectively. Three colonies from each plate were selected for biochemical characterization. Biochemical identification of the organisms being under study was made using the method described by Barrow and Feltham [34]. L. monocytogenes, Salmonella and Shigella colonies were biochemically identified using API Listeria and API 20E test kits (BioMerieux Inc., Lyon, France), respectively. The biochemical tests used to confirm $S$. aureus were coagulase test, catalase test, indole production, methyl red test, Vogesproskauer reaction, urease production, citrate utilization and sugar fermentation. The existence of coliforms and E. coli in samples of burgers was also tested using the most probable number (MPN) method [33]. First, mold and yeasts were detected and enumerated by diluting $1 \mathrm{~g}$ of burger sample in $9 \mathrm{~mL}$ of $0.1 \%$ peptonate water (Conda, Madrid, Spain), then, they were let for a two minute of homogenization. Subsequently, serial dilutions were made using $0.1 \%$ peptonate water. After that, samples were plated, using potato dextrose agar (Conda, Madrid, Spain) acidified to $\mathrm{pH} 3.5$ with $10 \%$ tartaric acid solution. Next, all plates were incubated at $25^{\circ} \mathrm{C}$ and colonies were counted after $72 \mathrm{~h}$. The results were expressed as $\mathrm{CFU} / \mathrm{g}$.

2.7. Statistical Analysis. All analyses were done in triplicates. Values were expressed as mean \pm SD. One-way ANOVA and Duncan's multiple comparison tests were applied to compare the results with statistically significant differences for $\mathrm{p}$ values $(P<0.05)$. Version 19 of the IBM SPSS statistics software (IBM Corp., Armonk, NY, USA) was used to perform all statistical analysis.

\section{Results and Discussion}

3.1. Physical and Chemical Characterization of Algae Powders. The compositions of algae (C. compressa and J. adhaerens) powders have been analyzed and the results are presented in Table 1 . The crude fat and proteins contents were around $2.8 \%$ and $9.9 \%$, respectively, irrespective of the type of algae. Ash content was high, $39.56 \%$, in C. compressa, while J. adhaerens had the lowest ash content (36.83\%) and the highest moisture $(12.64 \%)$. Total dietary fiber (TDF) of algae ranged from $51.68 \%$ to $57.33 \%$, with differences in the content of the insoluble and soluble dietary fiber fractions [35]. Powder algae $\left(\mathrm{pH}=(6.88-6.91) ; \mathrm{a}_{\mathrm{w}}=(0.35-0.41)\right)$ contained between 34.54 and $39.11 \%$ of total sugars, principally neutral, between 28.06 and $30.49 \%$, with minor amounts of uronic acids between $4.05 \%$ and $11.05 \%$. These chemical attributes were confirmed qualitatively by FT-IR analysis (Figure 1). The chemical content of the two studied algae was within the range reported by various authors for brown and red algae $[35,36]$. Fibers and polysaccharides closely associated with cell wall proteins might also play a role in physicochemical properties of algae such as water-holding (9.57-13.82 g/g DW) 
TABLE 1: The composition analysis of algae powder.

\begin{tabular}{|c|c|c|}
\hline Items & C. compressa & J. adhaerens \\
\hline \multicolumn{3}{|c|}{ Physical and functional properties } \\
\hline $\mathrm{pH}$ & $6.91 \pm 0.02$ & $6.88 \pm 0.01$ \\
\hline $\mathrm{a}_{\mathrm{w}}$ & $0.35 \pm 0.01$ & $0.41 \pm 0.02$ \\
\hline $\mathrm{L}^{*}$ & $35.71 \pm 0.84$ & $36.54 \pm 0.18$ \\
\hline$a^{*}$ & $3.85 \pm 0.01$ & $21.05 \pm 0.21$ \\
\hline$b^{*}$ & $11.74 \pm 0.09$ & $14.22 \pm 0.23$ \\
\hline WHC (g of water/g DW) & $13.82 \pm 0.52$ & $9.57 \pm 0.31$ \\
\hline OHC (g of oil/g DW) & $3.80 \pm 0.26$ & $2.20 \pm 0.14$ \\
\hline \multicolumn{3}{|l|}{ Chemical properties } \\
\hline Moisture (\%) & $10.87 \pm 0.13$ & $12.64 \pm 0.24$ \\
\hline Total solids (\%) & $89.13 \pm 0.13$ & $87.35 \pm 0.24$ \\
\hline Protein (\%) & $9.98 \pm 0.19$ & $9.81 \pm 0.15$ \\
\hline Crude fat (\%) & $2.80 \pm 0.45$ & $2.76 \pm 0.51$ \\
\hline Ash (\%) & $39.56 \pm 0.14$ & $36.83 \pm 0.28$ \\
\hline Total dietary fiber (\%) & $57.33 \pm 2.05$ & $51.68 \pm 1.36$ \\
\hline Total sugar $(\%)$ & $39.11 \pm 1.78$ & $34.54 \pm 1.15$ \\
\hline Neutral sugar (\%) & $28.06 \pm 0.51$ & $30.49 \pm 0.22$ \\
\hline Uronic acids (\%) & $11.05 \pm 0.55$ & $4.05 \pm 0.43$ \\
\hline Chlorophyll a (mg/g DW) & $16.78 \pm 0.42$ & $12.44 \pm 0.32$ \\
\hline Carotenoids (mg/g DW) & $6.85 \pm 0.19$ & $4.51 \pm 0.42$ \\
\hline Chlorophyll b (mg/g DW) & $0.92 \pm 0.07$ & $0.50 \pm 0.01$ \\
\hline Scavenging activity $(\%)^{*}$ & $97.33 \pm 2.45$ & $82.29 \pm 1.98$ \\
\hline Reducing power* & $1.47 \pm 0.12$ & $0.88 \pm 0.09$ \\
\hline
\end{tabular}

Values are expressed as means \pm standard deviations of triplicates. ${ }^{*}:$ the DPPH scavenging activity and the reducing power were evaluated at a samples concentration of $10 \mathrm{mg} / \mathrm{mL}$.

and oil-absorption (2.2-3.8 g/g DW) capacities [1, 13], which suggests it might be able to stabilize food emulsion [36].

Brown seaweed (C. compressa) presented a variety of shades ranging from dark green to dark chestnut by way of yellowish-greens and masking the green of the chlorophyll with the existence of phycophin and xanthophyll where $\mathrm{L}^{*}$ values were higher than $b^{*}$ values). However, the range of colorings from pink to red in Jania (red seaweed) is a result of the combination of chlorophyll, phycoerythrin and phycocyanin (high $\mathrm{a}^{*}$ values) (Table 1). The pigments composition had a positive correlation with antioxidant activity as previously described $[1,13]$. At $10 \mathrm{mg} / \mathrm{mL}$, the ethanolic extract of Cystoseira powder exhibited higher DPPH scavenging activity (97.33\%) that was higher than that for Jania powder (82.29\%). A similar tendency was also observed for FRAP (Table 1). Due to their important biochemical characteristics (high content of dietary fiber and polysaccharides), C. compressa and J. adhaerens can potentially be used as natural ingredients to produce functional and nutritional food products and can be a healthy food source.

3.2. Technological Process. Actually, freshness highly contributes to the quality of fresh fish which is a greatly perishable product. The principal method to assess this parameter is sensory evaluation. The sensory evaluation method used in this study was the Quality Index Method (QIM) developed by the Tasmanian Food Research Unit [37]. According to this method, notes from 0 to $1 ; 0$ to 2 or 0 to 3 demerit points (or indexes) were attributed to the changes in the smell, texture, appearance and color of the eyes, skin and gills of fish. The points attributed to barbel quality were summed up to give an overall sensory score or an overall quality index (IQ) equal to 6 (complete score 6/6). By comparing this value with the standard calibration curve, it was concluded that the raw material of this study reflected good sensory, microbiological and hygienic quality. In addition, this quality index provided a quantitative estimate of the shelf-life of this product with satisfactory precision. In the current study, fish are classified into 3 size categories (small, medium or large) based on their weight (Table 2). The yields we obtained during fish fillets preparation are illustrated by Table 2 . The results showed a non-significant difference of yields for small or medium weight $(P>0.05)$ contrary to those obtained with the large one. Indeed, higher yields of fillets (44\%) were obtained using large fish. These results could be explained by the difficulty of handling small fish. The yields of flesh, minced flesh and burgers were evaluated for the three fish categories. Hence, it was possible to transform a quantity of freshwater fish of $10 \mathrm{~kg}$ into around $3.6 \mathrm{~kg}$ of burger, including the ingredients added to the formulation, distributed among 36 cans (Figure 2).

3.3. Preliminary Results. Dried and ground C. compressa and $J$. adhaerens were added at $0.5,1$ and $1.5 \%(\mathrm{w} / \mathrm{w})$ as dietary fiber and phycocolloids in the barbel burgers. Then 


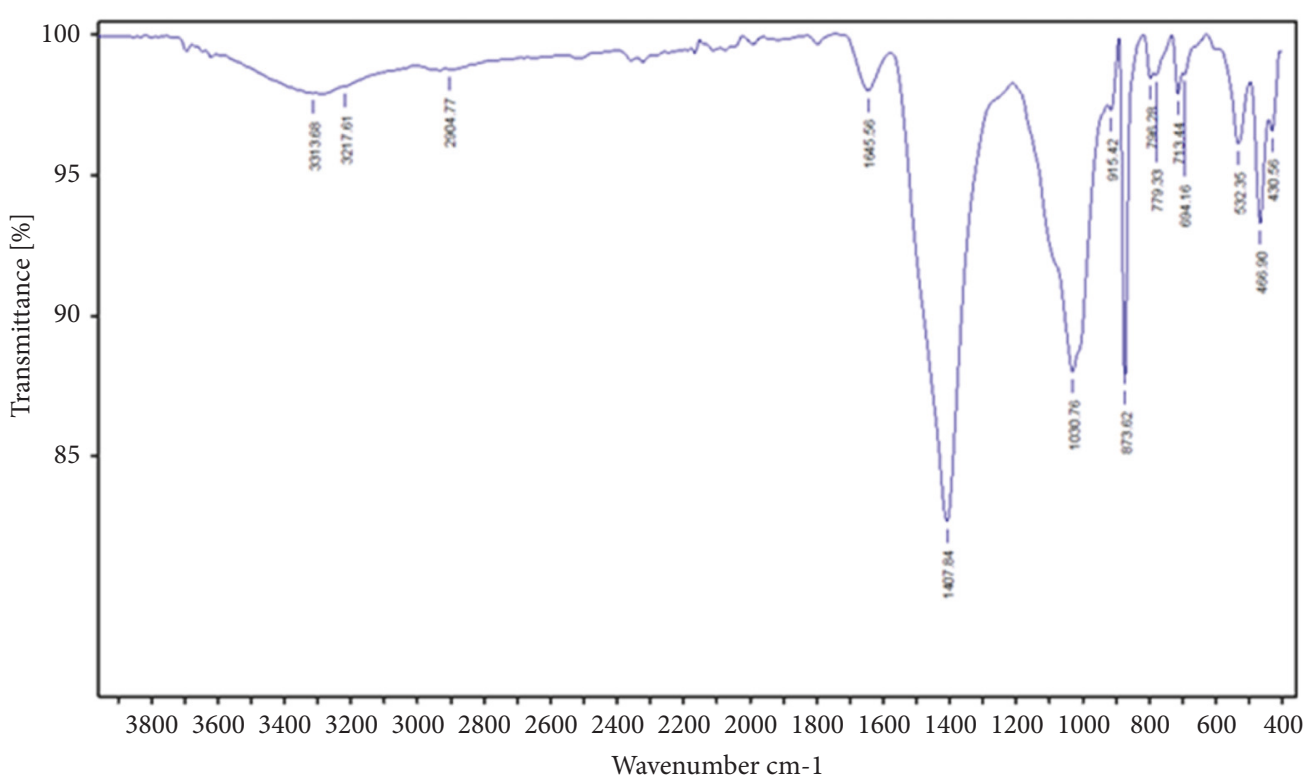

(a)

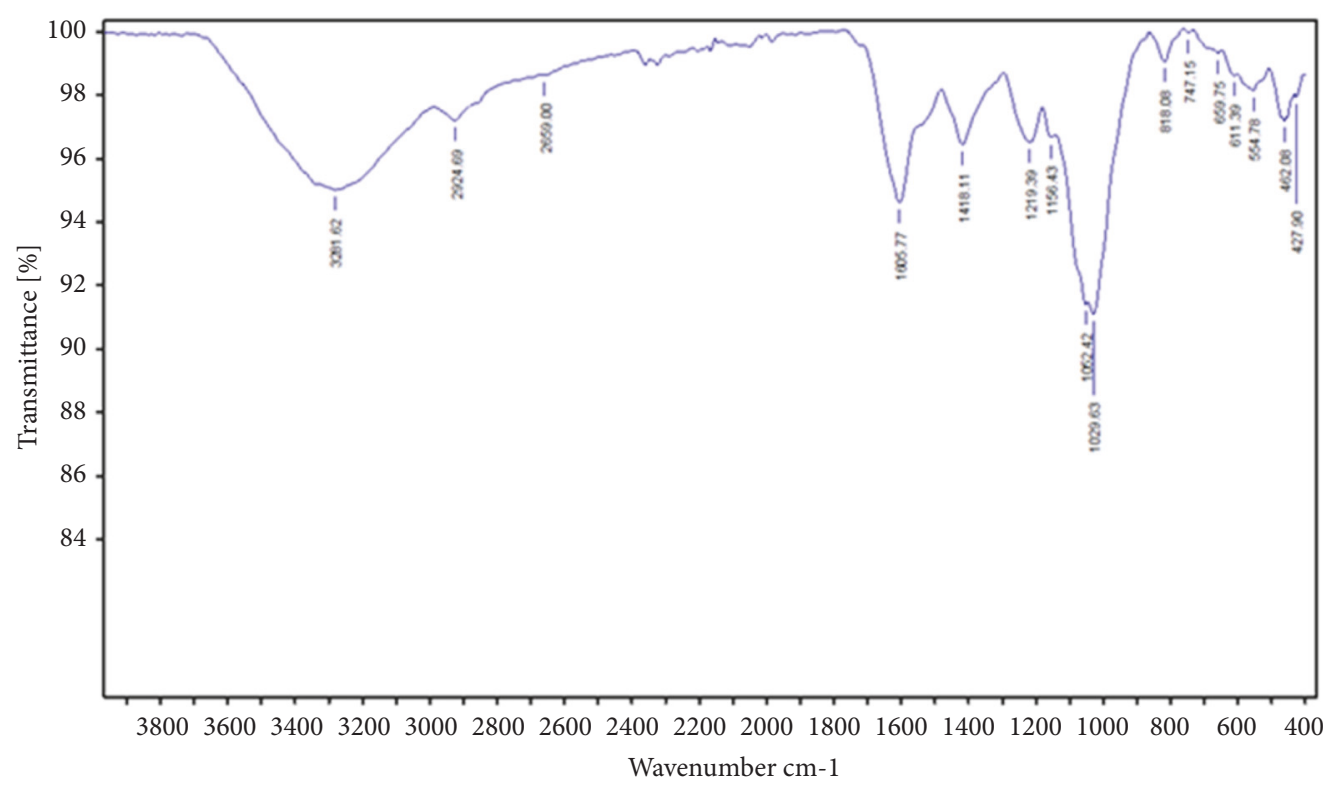

(b)

FIgURE 1: FT-IR spectra of the powder of (a) C. compressa (brown algae) and (b) J. adhaerens (red algae).

the burgers were tested for their physicochemical, textural and sensory properties.

The results of these analyses are summarized in Table 3. Fish burgers without algae and containing the lower percentages of brown and red algae $(0.5 \%$ and $1 \%$, w/w) had the highest sensory scores $(P<0.05)$. These results were similar to those of Barkallah et al. [27] who revealed that fortified burgers with low Spirulina percentages had high sensory and textural qualities. The additions of high percentages of the two algae $(1.5 \%)$ in the barbel burgers had the lowest levels of taste, color, flavor and general acceptability $(P<$ 0.05). Furthermore, the existence of an inappropriate flavor, explained by the production of products promoting lipid oxidation as well as the production of metallic flavors by minerals from the algae has been noted. While, the algae powder macrostructure decreased $(P<0.05)$ the burger flavor scores for $1.5 \%$ (scores of 7.23 and 7.4 ), there was no significant difference for this parameter between control burgers and burgers supplemented with $1 \%$ of algae $(P=0.553(\mathrm{~J}$. adhaerens) and $P=0.999$ (C. compressa)). The algal addition at several percentages enhanced texture scores $(P<0.05)$. Indeed, this improvement $(P<0.05)$ was mainly observed by adding C. compressa (0.5\%) and J. adhaerens (1\%) (scores of 8.19 and 8.16 instead of 7.96 for the control). Moreover, it was noticed that the fish burgers' color with the greatest percentage of algae (1.5\%) changed from yellowish to a darker 
TABLE 2: Yields of steps of burger preparation.

\begin{tabular}{lccc}
\hline Barbel size & Category 1 & Category 2* & ${\text { Category } 3^{*}}^{*}$ \\
\hline Yields (\%) & & & $78.48 \pm 1.61^{\mathrm{B}, \mathrm{C}}$ \\
After heading & $79.88 \pm 0.68$ & $78.46 \pm 1.76$ & $65.31 \pm 0.7^{\mathrm{B}, \mathrm{C}}$ \\
After evisceration and flaking & $56.35 \pm 0.85$ & $60.14 \pm 0.25$ & $44.05 \pm 0.67^{\mathrm{B}, \mathrm{C}}$ \\
After fileting & $39.45 \pm 0.15$ & $39.99 \pm 1.07$ & \\
Total yields of fish fillets transformation steps (\%) & & $41.16 \pm 1.92$ \\
Total flesh yield & & $37.56 \pm 1.81$ \\
Minced flesh yields & & $34.52 \pm 1.92$ \\
Burger & & & \\
\hline
\end{tabular}

${ }^{*}$ : fish are classified into 3 size categories (small $(730 \pm 20 \mathrm{~g})$, medium $(1341 \pm 60 \mathrm{~g})$, or large $(2110 \pm 85 \mathrm{~g})$ ) based on their weight.

(\%) All the yields of the different stages are calculated in grams of meat obtained after each stage with respect to the initial weight of fish.

Category 1 versus Category 2: ${ }^{\mathrm{A}} P<0.05$.

Category 1 versus Category $3:{ }^{\mathrm{B}} P<0.05$.

Category 2 versus Category $3:{ }^{C} P<0.05$.

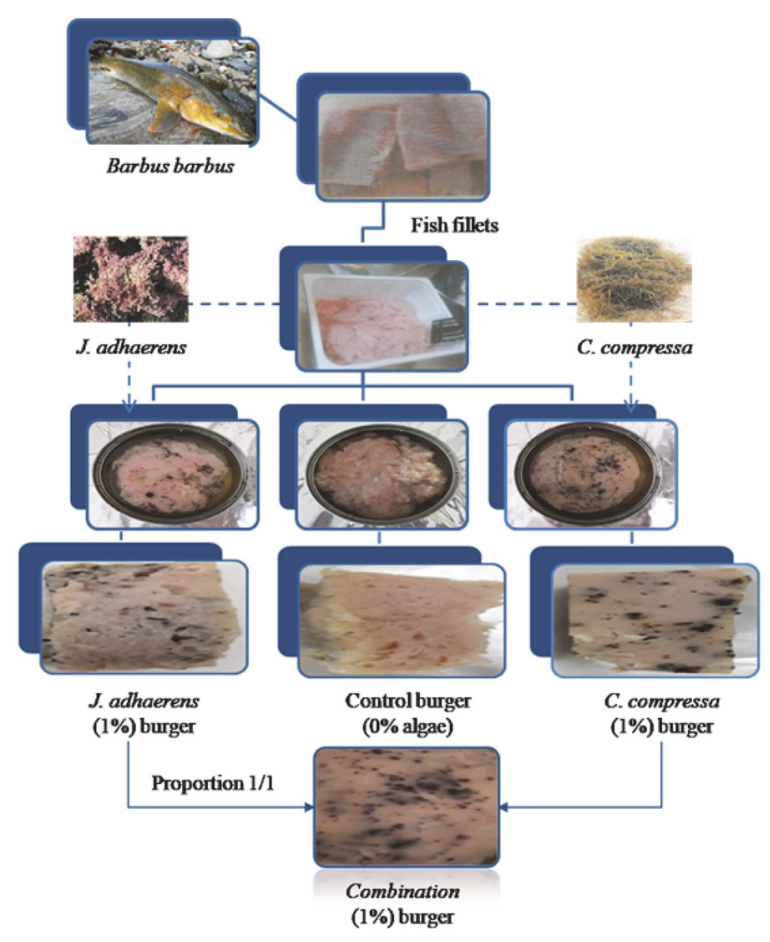

FIGURE 2: Diagram describing the main stages of the manufacturing process of common barbel fish burgers.

color and this was considered as an inappropriate sensory characteristic (bad appearance) by the panelists $(P<0.05)$. In addition, the burgers containing this percentage of algae had also the lowest scores of mouth tastes and overall acceptability $(P<0.05)$ for the presence of insoluble particles from algae. Generally, there was no important difference for these parameters between control burgers and those supplemented with lower quantities of algae. Fish burgers made with algae powder $(1 \%)$ were found to be firmer and less greasy. It seems that the absence of greasy films observed for these burgers reinforced the sensory perception of the firmness as well as the improvement of the visual texture $[1,13]$. The changes in texture were one of the most important parameters for assessing and addressing the difficulties found in functional foods $[1,28]$. This key tool, strongly correlated with sensory properties, was used to determine the organoleptic quality of fish burgers [38]. The values of texture parameters (hardness, elasticity and cohesiveness) of control and burgers with different percentages of $J$. adhaerens and C. compressa are illustrated in Table 3 . The addition of the two algae in all formulations increased the hardness and elasticity of burgers $(P$ $<0.05)$. These results were similar to the work of FernandezMartin et al. [39] where the addition of algae (Wakame and Nori) in pork meat significantly improved its hardness and elasticity. The important hardness and elasticity values were mainly detected for burgers with $1 \%$ of $J$. adhaerens and $C$. 


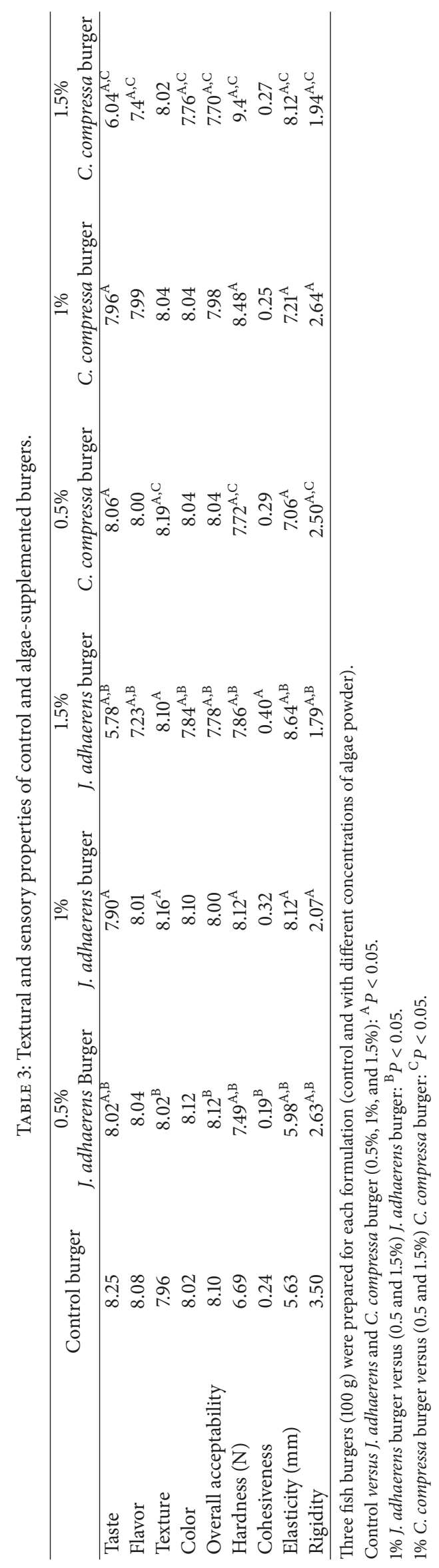


TABLE 4: Physicochemical and biochemical characterizations of control and algae-supplemented burgers (1\%).

\begin{tabular}{lcccc}
\hline & Control burger & 1\% J. adhaerens burger & 1\% C. compressa burger & Combination burger \\
\hline Moisture (\% FW) & $77.57 \pm 0.32$ & $76.89 \pm 0.11^{\mathrm{A}, \mathrm{B}}$ & $76.55 \pm 0.295^{\mathrm{A}}$ & $76.87 \pm 0.025^{\mathrm{A}, \mathrm{B}}$ \\
Total solids (\% FW) & $22.43 \pm 0.32$ & $23.11 \pm 0.11^{\mathrm{A}, \mathrm{B}}$ & $23.45 \pm 0.295^{\mathrm{A}}$ & $23.13 \pm 0.025^{\mathrm{A}, \mathrm{B}}$ \\
Protein (\% DW) & $78.25 \pm 0.125$ & $77.90 \pm 0.055$ & $77.55 \pm 0.095$ & $77.65 \pm 0.2$ \\
Fat (\% DW) & $8.34 \pm 0.085$ & $7.97 \pm 0.035$ & $8.15 \pm 0.10$ & $8.35 \pm 0.09$ \\
Ash (\% DW) & $11.53 \pm 0.03$ & $11.86 \pm 0.105^{\mathrm{A}}$ & $13.06 \pm 0.097^{\mathrm{A}}$ & $12.73 \pm 0.165^{\mathrm{A}}$ \\
Total dietary fiber (g/100 g DW) ${ }^{*}$ & $0.20 \pm 0.01$ & $0.36 \pm 0.04^{\mathrm{A}, \mathrm{B}}$ & $0.62 \pm 0.13^{\mathrm{A}}$ & $0.50 \pm 0.07^{\mathrm{A}, \mathrm{B}}$ \\
Solid pH & $7.14 \pm 0.02$ & $7.12 \pm 0.005$ & $7.04 \pm 0.015^{\mathrm{A}}$ & $7.05 \pm 0.0^{\mathrm{A}}$ \\
$\mathrm{a}_{\mathrm{w}}$ (wet) & $0.983 \pm 0.002$ & $0.973 \pm 0.002^{\mathrm{A}, \mathrm{B}}$ & $0.963 \pm 0.002^{\mathrm{A}}$ & $0.970 \pm 0.001^{\mathrm{A}}$ \\
$\mathrm{a}_{\mathrm{w}}$ (dry) & $0.205 \pm 0.005$ & $0.198 \pm 0.0^{\mathrm{A}}$ & $0.195 \pm 0.002^{\mathrm{A}}$ & $0.192 \pm 0.002$ \\
SWC (mL/g DW) & $3.365 \pm 0.02^{\mathrm{A}, \mathrm{B}}$ & $3.56 \pm 0.020^{\mathrm{A}}$ & $3.435 \pm 0.015^{\mathrm{A}}$ \\
WHC (g/g DW) & $2.997 \pm 0.023$ & $2.61 \pm 0.07^{\mathrm{A}}$ & $2.62 \pm 0.023^{\mathrm{A}}$ & $2.59 \pm 0.015^{\mathrm{A}}$ \\
OHC (g/g DW) & $2.12 \pm 0.03$ & $1.10 \pm 0.02^{\mathrm{A}}$ & $1.12 \pm 0.025^{\mathrm{A}}$ & $1.14 \pm 0.02^{\mathrm{A}}$ \\
\hline
\end{tabular}

Three fish burgers (100 g) were prepared for each formulation (control and with different concentrations of algae powder). Control vs. (1\% J. adhaerens, $1 \%$ C. compressa and $1 \%$ combination) burger: ${ }^{\mathrm{A}} \mathrm{P}<0.05$.

$1 \%$ C. compressa burger $v s$. (1\% J. adhaerens and $1 \%$ combination) burger: ${ }^{\mathrm{B}} P<0.05$.

${ }^{*}$ Results are expressed as means \pm SD $(n=3)$.

The (\%) is calculated relative to a dry weight basis $(D W)$ for lipid, protein and ash whereas the moisture content and total solids are expressed with respect to a fresh weight basis $(F W)$.

compressa which had values of $8.12 \mathrm{~N}$ and $8.12 \mathrm{~mm}$ as well as $8.48 \mathrm{~N}$ and $7.21 \mathrm{~mm}$, respectively. The cohesiveness of the control burger $(0.24)$ was similar to that recorded in burgers containing $1 \%$ of $C$. compressa (0.25). This result differs from that published by Cofrades et al. [35] who evaluated the decrease in cohesiveness and resistance of gel/emulsion food systems after adding three edible algae (H. elongata, $U$. Pinnatifida and P. umbilicalis) in them. The higher amount of algae in burgers $(1.5 \%)$ considerably affected $(P<0.05)$ the texture and rigidity of the final product (1.79 and 1.94) by disrupting the arrangement network of algal particles in fish burger $[1,13]$. By contrast, the incorporation of $0.5 \%$ or $1 \%$ of the two algae in barbel burgers did not significantly change the cohesiveness recorded with the control. Hence, it was estimated that the supplementations of burgers with $1 \%$ of $C$. compressa or J. adhaerens both conserved and improved the textural characteristics and sensory acceptability of the final products already accepted by the panelists. Based on these sensorial and textural criteria, fish burgers enriched with $1 \%$ of algae were selected for further analyses so as to assess their functional, physicochemical microbiological and antioxidant properties. Added to that, the incorporation of a combination $(1 \%,(\mathrm{w} / \mathrm{w}))$ of C. compressa/J. adhaerens (proportions of $1 / 1$ ) was prepared.

3.4. Nutritional Properties of Fish Burger. The moisture content, total solids, ash, protein and lipid contents of burgers are provided in Table 4 . The chemical composition analysis of control burger showed its richness in water $(77.57 \%$ in relation to the fresh weight). The total solids (TS) content was $22.43 \%$ (relative to fresh weight) and its consisted in $78.25 \%$ proteins, $8.34 \%$ lipids and $11.53 \%$ ashes. These results are in agreement with those found by Ben Atitallah et al. [1], Siddaiah et al. [40], and Vanitha et al. [41] for fish burgers made with Cyprinus carpio, Hypophthalmichthys molitrix and
Catla catla. In this study, adding algae $(1 \%, w / w)$ considerably improved the levels of the total solids $(P<0.05)$ and ash $(P<$ 0.05). The decrease of proteins and lipids contents of burgers supplemented with algae compared to control seemed as if they would be non-significant $(P>0.05)$. This reduction confirmed the natural richness of freshwater fish in proteins and lipids $[1,13]$. The highest values of total solids $(P<0.05)$ and ash $(P<0.05)$ were found in burgers supplemented with C. compressa (Table 4), showing the initial richness of brown algae in total solids and ash. Similarly, the combination of $1 \%$ (w/w) C. compressa/J. adhaerens (proportions of 1/1)) exerted a greater effect than that recorded after the sole addition of $J$. adhaerens $(P<0.05)$.

\subsection{Chemical Composition and Antioxidant Potential of Fish} Burgers. These nutritional characteristics were qualitatively confirmed by FTIR analysis. The infrared spectrum of the control samples demonstrated some differences compared to those of the algae-supplemented burgers (Figure 3). The spectra showed a strong and wide absorption peak at 3272 $\mathrm{cm}^{-1}$ corresponding to the hydroxyl $(\mathrm{O}-\mathrm{H})$ stretching vibration of proteins, polysaccharides (such as glycogen from fish muscle and hydrocolloids from algae) and water. The strong absorption in the region of $3000 \mathrm{~cm}^{-1}$ and $2800 \mathrm{~cm}^{-1}$ proved the presence of the $\mathrm{NH}_{2}$ groups, which reflected the high content of protein in burgers. The bands at 1636 $\mathrm{cm}^{-1}$ (1590-1650 $\left.\mathrm{cm}^{-1}\right)$, corresponded to the $(\mathrm{NH})$ and $(\mathrm{C}=\mathrm{O})$ groups of amides $\mathrm{I}$, and the absorption band at 1516 $\mathrm{cm}^{-1}$ (between 1500 and $1560 \mathrm{~cm}^{-1}$ ) indicated the existence of $(\mathrm{NH})$ groups and asymmetric $(\mathrm{N}=\mathrm{O})$ groups of amide II [42]. Lipids were characterized by the existence of an absorption peak at $1742 \mathrm{~cm}^{-1}$ suggesting the presence of ester groups $(\mathrm{C}=\mathrm{O})$ of hydrocolloids, while those at 1457 $\mathrm{cm}^{-1}$ and $1376 \mathrm{~cm}^{-1}$ mainly presented the $\mathrm{C}-\mathrm{OH}$ stretching 


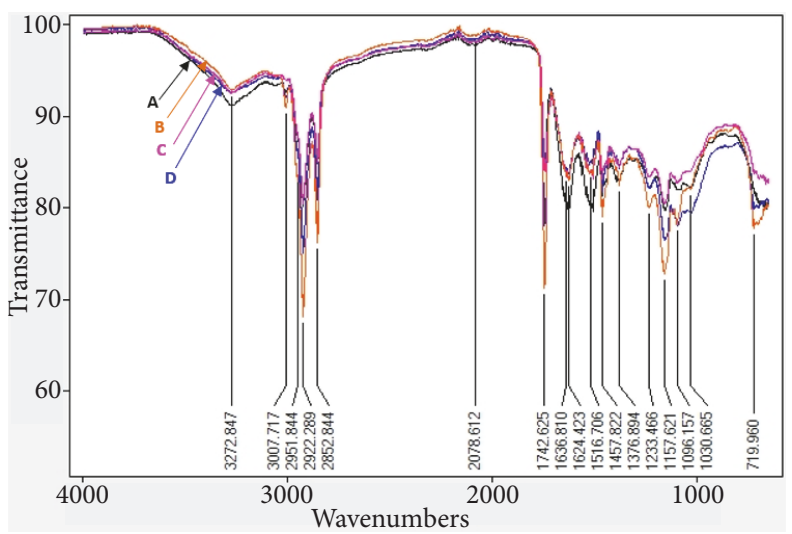

FIGURE 3: FT-IR analysis of (A) control burger, (B) 1\% C. compressa burger, (C) $1 \%$ J. adhaerens burger, and (D) $1 \%$ combination burger.

TABLE 5: Pigment equipment and antioxidant activity of fish burgers (with and without algae).

\begin{tabular}{lcccc}
\hline & Control burger & J. adhaerens Burger & $\begin{array}{c}1 \% \\
\text { C. compressa burger }\end{array}$ & $\begin{array}{c}1 \% \\
\text { Combination burger }\end{array}$ \\
\hline $\begin{array}{l}\text { Chlorophyll a } \\
(\mathrm{mg} / 100 \text { g DW) }\end{array}$ & $\mathrm{ND}$ & $11.44 \pm 0.11^{\mathrm{A}, \mathrm{B}}$ & $16.92 \pm 0.28^{\mathrm{A}}$ & $12.25 \pm 0.48^{\mathrm{A}}$ \\
$\begin{array}{l}\text { Carotenoids } \\
(\mathrm{mg} / 100 \text { g DW) }\end{array}$ & $\mathrm{ND}$ & $4.43 \pm 0.22^{\mathrm{A}}$ & $6.95 \pm 0.38^{\mathrm{A}}$ & $6.17 \pm 0.14^{\mathrm{A}}$ \\
$\begin{array}{l}\text { Chlorophyll b } \\
(\mathrm{mg} / 100 \text { g DW) }\end{array}$ & $\mathrm{ND}$ & $0.25 \pm 0.012^{\mathrm{A}, \mathrm{B}}$ & $0.874 \pm 0.019^{\mathrm{A}}$ & $0.64 \pm 0.013^{\mathrm{A}, \mathrm{B}}$ \\
$\begin{array}{l}\text { Scavenging activity }(\%)^{*} \\
\text { Reducing power }\end{array}$ & 40.09 & $65.05^{\mathrm{A}, \mathrm{B}}$ & $88.29^{\mathrm{A}}$ & $73.71^{\mathrm{A}, \mathrm{B}}$ \\
\hline
\end{tabular}

Three fish burgers $(100 \mathrm{~g})$ were prepared for each formulation (control and with different concentrations of algae powder).

Control versus $\left(1 \%\right.$ J. adhaerens, $1 \%$ C. compressa, and $1 \%$ combination burger): ${ }^{\mathrm{A}} P<0.001$.

$1 \%$ C. compressa burger versus $1 \%$ J. adhaerens and $1 \%$ combination burger: ${ }^{\mathrm{B}} P<0.05$.

*: the scavenging activity of DPPH free radicals (\%) and the reducing power (absorbance at $700 \mathrm{~nm}$ ) were determined at a sample concentration of $10 \mathrm{mg} / \mathrm{mL}$.

vibrations of carboxylic acids [28]. The spectrum of barbel burger supplemented with $C$. compressa (1\%) revealed the presence of three characteristic bands at around 1030, 1100 and $1450 \mathrm{~cm}^{-1}$. These bands were attributed to guluronic, mannuronic units and sulfate groups $(\mathrm{S}=\mathrm{O})$, respectively, suggesting the presence of alginate and sulphated fucoidans described in literature as matrix polysaccharides of Cystoseira species [8].

The pigments rate, DPPH-radical scavenging activity and reducing power (FRAP) were determined to evaluate algae contribution to the antioxidant properties of the resulting fish burgers (Table 5). All ethanolic extracts of burgers showed an anti-DPPH and reducing power activities at a concentration of $10 \mathrm{mg} / \mathrm{mL}$ (Table 5). The incorporation of algae not only significantly improved chlorophylls $(P<0.05)$, carotenoids $(P<0.05)$, and free radical scavenging but also reduced iron (reducing power) levels. The extracts with $C$. compressa had both higher DPPH free radical scavenging activity and reducing power $(P<0.05)$ than those with J.adhaerens. These antioxidant activities were correlated with pigments and carotenoids equipment of the two algae (Table 5) $[1,13,19]$. Fish burgers supplemented with $J$. adhaerens that contained lower quantities of chlorophylls ( $a$ and $b$ ) had an antiradical activity $(65.05 \%)$ and a reducing power $(0.648)$ lower than those of burgers with C. compressa (88.29\% and 0.837) ( $P$ $<0.05)$. The combination of the two algae had an important reinforcing effect on the DPPH free-radical scavenging (73.71\%) and iron reducing power (0.642) activities compared to the burgers treated only with $J$. adhaerens $(P<0.05)$. These results seems to be similar to that in the studies carried out by Jónsdóttir et al. [12] and Wang et al. [43] revealing an antiDPPH and reduction oxygen radical capacities of seafoods extracts containing $F$. vesiculosus (brown algae). Wang et al. [43] noted the strong antioxidant potential of phlorotannin from F. vesiculosus (polymeric phlorotannin-rich subfractions) to be used as a natural antioxidant supplement in fish muscle and fishery products. Cox and Abu-Ghannam [10] evaluated the effect of the addition of Sea Spaghetti as a source of antioxidants, dietary fiber, total phenols, and radical scavenging activity (DPPH) in cooked beef patties. The results showed that the antiradical activities of algaeenriched beef patties correlated with their polyphenol and pigment contents $[1,13,44]$. In their work, Andrade et al. [45] noted the important role of polyunsaturated fatty acids, phenolic compounds, chlorophylls and carotenoids in the improvement of the antioxidant potentials of food products. Moreover, the high antioxidant and iron reducing power could not be attributed only to the single class of compounds 
TABLE 6: Color analysis of different samples of fish burger powder by evaluating classical and polar coordinates.

\begin{tabular}{lcccc}
\hline & Control & $1 \%$ & $1 \%$ & $1 \%$ \\
& Burger & J. adhaerens Burger & C. compressa burger & Combination burger \\
\hline $\mathrm{L}^{*}$ & $40.6 \pm 0.05$ & $38.71 \pm 0.17^{\mathrm{A}}$ & $33.28 \pm 0.38^{\mathrm{A}}$ & $34.42 \pm 1.15^{\mathrm{A}}$ \\
$\mathrm{a}^{*}$ & $8.18 \pm 0.06$ & $5.62 \pm 0.08^{\mathrm{A}}$ & $5.2 \pm 0.07^{\mathrm{A}}$ & $5.39 \pm 0.11^{\mathrm{A}}$ \\
$\mathrm{b}^{*}$ & $18.11 \pm 0.47$ & $14.32 \pm 0.09^{\mathrm{A}}$ & $9.73 \pm 0.0^{\mathrm{A}}$ & $9.53 \pm 1.01^{\mathrm{A}}$ \\
$\mathrm{h}^{*}$ & $65.69 \pm 0.007$ & $68.57 \pm 0.002^{\mathrm{A}}$ & $61.86 \pm 0.006^{\mathrm{A}}$ & $60.53 \pm 0.04^{\mathrm{A}}$ \\
$\mathrm{C}^{*}$ & $19.87 \pm 0.45$ & $15.38 \pm 0.11^{\mathrm{A}}$ & $11.03 \pm 0.03^{\mathrm{A}}$ & $10.95 \pm 0.93^{\mathrm{A}}$ \\
\hline
\end{tabular}

Three fish burgers $(100 \mathrm{~g})$ were prepared for each formulation (control and with different concentrations of algae powder).

Control vs. (1\% J. adhaerens, $1 \%$ C. compressa and $1 \%$ combination burger): ${ }^{\mathrm{A}} \mathrm{p}<0.05 .\left(\mathrm{L}^{*}, \mathrm{~b}^{*}\right.$, and $\left.\mathrm{a}^{*}\right)$ are classical coordinates; $\left(\mathrm{L}^{*}, \mathrm{C}^{*}\right.$, and $\left.\mathrm{h}^{*}\right)$ shows polar coordinates.

$\mathrm{L}^{*}$ represents lightness, $\mathrm{a}^{*}$ represents redness, $\mathrm{b}^{*}$ represents yellowness.

(polysaccharides, sterols, tannins, mannitol and carotenoids) but also to the synergistic effect between all these molecules [46].

\subsection{Quality and Shelf-Life Measurements}

3.6.1. Physical and Functional Properties of Fish Burgers. Table 4 illustrated both the physical $\left(\mathrm{a}_{\mathrm{w}}\right.$ and $\left.\mathrm{pH}\right)$ and functional (WHC, OHC and SWC) characteristics of control and algae-fortified fish burgers. The control burger $\mathrm{a}_{\mathrm{w}}$ was estimated at 0.983 and 0.205 for fresh and dry conditions, respectively. The addition of algae powder in burgers significantly decreased the values of $\mathrm{a}_{\mathrm{w}}$ of fresh and dry burgers $(P<0.05)$. The burger supplemented with the alga having the highest fiber content (C. compressa) had the lowest $\mathrm{a}_{\mathrm{w}}$. These results were in accordance with those reported by Jridi et al. [28], who highlighted an important decrease in the $a_{w}$ of dairy desserts prepared with Allig variety highly rich in fibers compared to other varieties of dates. The combination of the two algae in a same burger improved the qualities of finished products $(P=0.01)$ as shown by the weak level of $a_{w}$ of this burger. This result could be explained by the effect of the fiber combination and might contribute to maintain a good microbiological quality. The $\mathrm{pH}$ values of different formulations indicated that the control burger presented higher $\mathrm{pH}$ values than that of algae supplemented one (7.14). The addition of $C$. compressa (alone or in a mix with $J$. adhaerens) in burgers decreased this parameter $(P<0.05)$ by making it closer to neutrality (7.04 and 7.05). This very decrease might be attributed to the acid nature of algae which was added to the formulations ( $\mathrm{pH}$ 6).

Water holding capacity and oil absorption property mean the ability to associate with water and oil, respectively [36]. As illustrated in Table 4, the addition of the two algae at (1\%) significantly increased $(P<0.05)$ the WHC, OHC and SWC values of fish burgers compared to controls, highlighting its richness of texturing compounds that play an important role in improving the food texture stability throughout the storage period [28]. These results were similar to those obtained by Ben Atitallah et al. [1,13], Cox \& Abu-Ghannam [10], and Senthil et al. [43]. In their studies, Cox \& Abu-Ghannam [10], López-López et al. [47], and López-López et al. [48] have shown that the addition of the edible Himanthalia elongata (Sea Spaghetti) in beef and hog products improved their water and oil retention capacities. Our study demonstrated that fish burger supplemented with $1 \%$ of $C$. compressa had higher SWC values $(P=0.0125)$ than that enriched with $1 \%$ of $J$. adhaerens. Considering WHC and OHC of these two burgers, no significant differences were measured $(P>$ $0.05)$. These WHC and OHC were mainly attributed to the existence of large amounts of algal polysaccharides, which were a potential source of soluble and insoluble dietary fibers [44]. Insoluble fibers can influence the texture of foods not only because of their ability to absorb and maintain water but also due to their swelling characteristics. Indeed, these insoluble compounds can improve the coherence of meat products by forming an insoluble three-dimensional network [49]. The level of fibers in C. compressa was significantly higher $(P=0.005)$ than that of J. adhaerens. The combination of algae $(1 \% \mathrm{w} / \mathrm{w})$ in burgers contributed to the formation of a more heterogeneous structure. So, there was a synergic effect of the two algae on the properties of our burger matrix [50].

3.6.2. Color Analysis of Fish Burgers. Actually, color is one of the main parameters in determining the consumer acceptance of food products [35]. In the current study, it has been evaluated by two types of conventional and polar coordinates in fish burgers. The CIE-Lab color parameters $\left(\mathrm{L}^{*}, \mathrm{a}^{*}\right.$ and $\left.\mathrm{b}^{*}\right)$, chroma $\left(\mathrm{C}^{*}\right)$ and tint (shade) $\left(\mathrm{h}^{*}\right)$ of fish burgers are presented in Table 6 . As the burgers were formulated under the same experimental conditions, the changes in color were only the consequence of algae addition. Cofrades et al. [35] noted that the formulation of food products has undergone changes in color of meat products depending on their water, fat and pigments contents. This was confirmed in this study where the color attributes $\left(L^{*}, a^{*}, b^{*}, C^{*}\right.$ and $\left.h^{*}\right)$ were affected by the addition of brown and red algae to fish burgers. This difference in color depended mainly on the type of added marine algae. The supplementation of burger with C. compressa caused a significant and more pronounced decrease in coordinates $\left(\mathrm{L}^{*}, \mathrm{a}^{*}, \mathrm{~b}^{*}\right)(P<0.05)$. These results are similar to those obtained during the color analyses of fish burger mixed with Eucheuma [51]. The fish burgers with $1 \%$ of $J$. adhaerens had both the highest $\mathrm{L}^{*}$ and $\mathrm{b}^{*}$ values among the algal samples $(P<0.05)$ and the most important $\mathrm{h}^{*}$ values $(P<0.05)$, which indicated that their color tended to be red $\left(a^{*}=5.62\right)$. In contrast, the fish burgers enriched with $1 \%$ of $C$. compressa tended to decrease in the 
red color $\left(\mathrm{a}^{*}=5.2\right)$ compared to control $(P<0.05)$. The color of burger supplemented with a combination of the two algae did not significantly differ from that of burger treated with $C$. compressa $(P>0.05)$. Based on these findings, it might be concluded that the addition of these two algae significantly reduced the redness of fish burgers $(P<0.05)$, which suggested that the color of the final food product shifted from dark red to light red (red algae) or green (brown algae). This close relationship between redness and the type of the added algae in food was previously observed with Sea Spaghetti and Nori seaweeds by Cofrades et al. [35]. Moreover, Moroney et al. [9] studied the effect of adding algae extracts containing polysaccharides on the decrease in redness on the surface of the patties of fresh pigs. In the current study, all colors of fish burgers with algae were different from those found in the Wakame algal samples [35] where differences in $\mathrm{a}^{*}$ values were not important $(P>$ 0.05 ). The research carried out by Jiménez-Colmenero et al. [50] showed that the addition of Seafood Spaghetti/konjac gel caused a decrease in $\mathrm{L}^{*}$ and $\mathrm{a}^{*}$ values and an increase in the yellow hue $b^{*}$ of frankfurters. Similarly, Kim et al. [52] published the effect of algae incorporation (Laminaria japonica) on fresh pork hams and the decrease of $\mathrm{L}^{*}$ and $\mathrm{a}^{*}$ values. In contrast, Sasaki et al. [11] proved that on the one hand fucoxanthin reduced the lightness value $L^{*}$ and on the other hand it improved the values of $\mathrm{a}^{*}$ and $\mathrm{b}^{*}$ of ground chicken breast meat. These algae pigments could be used as stable natural dyes for applications in the fish canning industry.

3.6.3. Microbiology Quality Analysis of Fish Burgers. No mold, Enterobacteriaceae, yeast, coliform bacteria or foodborne pathogens (Salmonella spp., Shigella spp., L. monocytogenes, B. cereus, and Campylobacter spp.) were detected in any of the canned burgers during two months of storage at $4^{\circ} \mathrm{C}$ [1]. The absence of these pathogens suggested that the fish burgers were clean and safe even after a storage period. These microbiological results suggest that the production of the final fish product was carried out with good hygienic and sanitary practices. Note that these results have also been reported in numerous studies $[1,13,43]$.

\section{Conclusions}

Algae were effective natural additives to canned fish burgers. In addition to bringing nutritional components, algae might be a suitable source of beneficial natural flavoring and coloring agents. Furthermore, algae, rich in dietary fibers, maintained the texture of the final product by improving its functional properties (water and oil holding capacities). The addition of algae significantly improved both the physicochemical composition and the organoleptic acceptability of the final fish products without alteration of their microbiological quality. These algae treatments not only improved the nutritional content of the prepared fish products but also increased their antioxidant action. All these results could be used to potentially produce a canned fish burger prepared from minced flesh of common barbel enriched with algae as a natural source of bioactive substances (chlorophylls and carotenoids). The reasonable selection of these algae as fortifier agents in fish based products appears to be considerable, as it improves the healthfulness of foods.

\section{Data Availability}

The data used to support the findings of this study are available from the corresponding author upon request.

\section{Conflicts of Interest}

All authors declare no conflicts of interest.

\section{Acknowledgments}

All the authors are very grateful to the Tunisian Ministry of Higher Education for facilities.

\section{References}

[1] A. Ben Atitallah, M. Barkallah, F. Hentati et al., "Physicochemical, textural, antioxidant and sensory characteristics of microalgae-fortified canned fish burgers prepared from minced flesh of common barbel (Barbus barbus)," Food Bioscience, Article ID 100417, 2019.

[2] N. Gökoğlu and P. Yerlikaya, Refrigeration and Freezing: Science and Technology, John Wiley \& Sons, Ltd, Chichester, UK, 1st edition, 2015.

[3] G. Karanikolopoulos, A. Gerakis, K. Papadopoulou, and I. Mastrantoni, "Determination of synthetic food colorants in fish products by an HPLC-DAD method," Food Chemistry, vol. 177, pp. 197-203, 2015.

[4] A. Cedola, A. Cardinali, M. A. Del Nobile, and A. Conte, "Fish burger enriched by olive oil industrial by-product," Food Science \& Nutrition, vol. 5, no. 4, pp. 837-844, 2017.

[5] S. Randhawa and S. L. Bahna, "Hypersensitivity reactions to food additives," Current Opinion in Allergy and Clinical Immunology, vol. 9, no. 3, pp. 278-283, 2009.

[6] M. Carocho, M. F. Barreiro, P. Morales, and I. C. F. R. Ferreira, "Adding molecules to food, pros and cons: A review on synthetic and natural food additives," Comprehensive Reviews in Food Science and Food Safety, vol. 13, no. 4, pp. 377-399, 2014.

[7] S. Spinelli, L. Lecce, D. Likyova, M. A. Del Nobile, and A. Conte, "Bioactive compounds from orange epicarp to enrich fish burgers," Journal of the Science of Food and Agriculture, vol. 98, no. 7, pp. 2582-2586, 2018.

[8] F. Hentati, C. Delattre, A. V. Ursu et al., "Structural characterization and antioxidant activity of water-soluble polysaccharides from the Tunisian brown seaweed Cystoseira compressa," Carbohydrate Polymers, vol. 198, pp. 589-600, 2018.

[9] N. C. Moroney, M. N. O’Grady, J. V. O’Doherty, and J. P. Kerry, "Effect of a brown seaweed (Laminaria digitata) extract containing laminarin and fucoidan on the quality and shelf-life of fresh and cooked minced pork patties," Meat Science, vol. 94, no. 3, pp. 304-311, 2013.

[10] S. Cox and N. Abu-Ghannam, "Enhancement of the phytochemical and fibre content of beef patties with Himanthalia elongata seaweed," International Journal of Food Science \& Technology, vol. 48, no. 11, pp. 2239-2249, 2013.

[11] K. Sasaki, K. Ishihara, C. Oyamada et al., "Effects of fucoxanthin addition to ground chicken breast meat on lipid and colour 
stability during chilled storage, before and after cooking," AsianAustralasian Journal of Animal Sciences, vol. 21, no. 7, pp. 10671072, 2008.

[12] R. Jónsdóttir, M. Geirsdóttir, P. Y. Hamaguchi, P. Jamnik, H. G. Kristinsson, and I. Undeland, "The ability of in vitro antioxidant assays to predict the efficiency of a cod protein hydrolysate and brown seaweed extract to prevent oxidation in marine food model systems," Journal of the Science of Food and Agriculture, vol. 96, no. 6, pp. 2125-2135, 2016.

[13] A. Ben Atitallah, F. Hentati, M. Dammak et al., "Effect of microalgae incorporation on quality characteristics and functional and antioxidant capacities of ready-to-eat fish burgers made from common carp (Cyprinus carpio)," Applied Sciences, vol. 9, no. 9, Article ID 1830, 2019.

[14] AOAC, Official Methods of Analysis, Association of Official Analytical Chemists, Washington, DC, Wash, USA, 17th edition, 2000.

[15] M. Dubois, K. A. Gilles, J. K. Hamilton, P. A. Rebers, and F. Smith, "Colorimetric method for determination of sugars and related substances," Analytical Chemistry, vol. 28, no. 3, pp. 350$356,1956$.

[16] N. Blumenkrantz and G. Asboe Hansen, "New method for quantitative determination of uronic acids," Analytical Biochemistry, vol. 54, no. 2, pp. 484-489, 1973.

[17] K. V. Saralaya, Laboratory Manual for Courses in Canning, University of Agricultural Sciences, Bangalore, India, 1978.

[18] G. W. Latimer, Official Methods of Analysis of AOAC International, AOAC International, Gaithersburg, MD, USA, 2016.

[19] M. Barkallah, M. Dammak, I. Louati et al., "Effect of Spirulina platensis fortification on physicochemical, textural, antioxidant and sensory properties of yogurt during fermentation and storage," LWT- Food Science and Technology, vol. 84, pp. 323330, 2017.

[20] E. G. Bligh and W. J. Dyer, "A rapid method of total lipid extraction and purification," Canadian Journal of Physiology and Pharmacology, vol. 37, no. 8, pp. 911-917, 1959.

[21] H. K. Lichtenthaler and A. R. Wellburn, "Determination of total carotenoids and chlorophylls A and B of leaf in different solvents," Biochemical Society Transactions, vol. 11, pp. 591-592, 1985.

[22] P. Kumar, C. M. Ramakritinan, and A. K. Kumaraguru, "Solvent extraction and spectrophotometric determination of pigments of some algal species from the shore of puthumadam, southeast coast of India," International Journal of Oceans and Oceanography, vol. 4, no. 1, pp. 29-34, 2010.

[23] P. Bersuder, M. Hole, and G. Smith, "Antioxidants from a heated histidine-glucose model system. I: investigation of the antioxidant role of histidine and isolation of antioxidants by high-performance liquid chromatography," Journal of the American Oil Chemists' Society, vol. 75, no. 2, pp. 181-187, 1998.

[24] A. Yildirim, A. Mavi, and A. A. Kara, "Determination of antioxidant and antimicrobial activities of rumex crispus $\mathrm{L}$. extracts," Journal of Agricultural and Food Chemistry, vol. 49, no. 8, pp. 4083-4089, 2001.

[25] K. H. Wong and P. C. K. Cheung, "Nutritional evaluation of some subtropical red and green seaweeds. part I - proximate composition, amino acid profiles and some physicochemical properties," Food Chemistry, vol. 71, no. 4, pp. 475-482, 2000.

[26] B. O. Okezie and A. B. Bello, "Physicochemical and functional properties of winged bean flour and isolate compared with soy isolate," Journal of Food Science, vol. 53, no. 2, pp. 450-454, 1988.
[27] M. Barkallah, A. Ben Atitallah, F. Hentati et al., "Effect of spirulina platensis biomass with high polysaccharides content on quality attributes of common carp (Cyprinus carpio) and common barbel (Barbus barbus) fish burgers," Applied Sciences, vol. 9, no. 11, Article ID 2197, 2019.

[28] M. Jridi, N. Souissi, M. B. Salem, M. Ayadi, M. Nasri, and S. Azabou, "Tunisian date (Phoenix dactylifera L.) by-products: Characterization and potential effects on sensory, textural and antioxidant properties of dairy desserts," Food Chemistry, vol. 188, pp. 8-15, 2015.

[29] B. Borg, S. Mihrshahi, M. Griffin, C. Chamnan, A. Laillou, and F. T. Wieringa, "Crossover trial to test the acceptability of a locally produced lipid-based nutrient supplement (LNS) for children under 2 years in Cambodia: a study protocol," British Medical Journal Open, vol. 7, no. 9, Article ID e015958, 2017.

[30] N. Ben Halima, M. Borchani, I. Fendri et al., "Optimised amylases extraction from oat seeds and its impact on bread properties," International Journal of Biological Macromolecules, vol. 72, pp. 1213-1221, 2015.

[31] S. Abdelkafi, M. Labat, Z. B. A. Gam, J. Lorquin, L. Casalot, and S. Sayadi, "Optimized conditions for the synthesis of vanillic acid under hypersaline conditions by Halomonaselongata DSM 2581 T resting cells," World Journal of Microbiology and Biotechnology, vol. 24, no. 5, pp. 675-680, 2008.

[32] A. Chakchouk-Mtibaa, L. Elleuch, S. Smaoui et al., "An antilisterial bacterioc in BacFL31 produced by Enterococcus faecium FL31 with a novel structure containing hydroxyproline residues," Anaerobe, vol. 27, pp. 1-6, 2014.

[33] APHA, Compendium of Methods for the Microbiological Examination of Foods, F. P. Downes and K. Ito, Eds., American Public Health Association (APHA), Washington, DC, Wash, USA, 4th edition, 2001.

[34] G. I. Barrow and R. K. A. Feltham, Cowan and Steel's Manual for the Identification of Medical Bacteria, Cambridge University Press, Cambridge, UK, 3rd edition, 1993.

[35] S. Cofrades, I. López-López, M. T. Solas, L. Bravo, and F. Jiménez-Colmenero, "Influence of different types and proportions of added edible seaweeds on characteristics of low-salt gel/emulsion meat systems," Meat Science, vol. 79, no. 4, pp. 767$776,2008$.

[36] M. Huang and H. Yang, "Eucheuma powder as a partial flour replacement and its effect on the properties of sponge cake," LWT, vol. 110, pp. 262-268, 2019.

[37] H. A. Bremner, "A convenient easy to use system for estimating the quality of chilled seafood," Fish Processing Bulletin, vol. 7, pp. 59-70, 1985.

[38] C. M. Steele, W. A. Alsanei, S. Ayanikalath, C. E. Barbon, J. Chen, and H. Wang, "The influence of food texture and liquid consistency modification on swallowing physiology and function: a systematic review," Dysphagia, vol. 30, pp. 2-26, 2015.

[39] F. Fernández-Martín, I. López-López, S. Cofrades, and F. J. Colmenero, "Influence of adding Sea Spaghetti seaweed and replacing the animal fat with olive oil or a konjac gel on pork meat batter gelation. Potential protein/alginate association," Meat Science, vol. 83, no. 2, pp. 209-217, 2009.

[40] D. Siddaiah, G. V. Sagar Reddy, C. V. Raju, and T. C. Chandrasekhar, "Changes in lipids, proteins and kamaboko forming ability of silver carp (Hypophthalmichthys molitrix) mince during frozen storage," Food Research International, vol. 34, no. 1, pp. 47-53, 2001. 
[41] M. Vanitha, K. Dhanapal, and G. Vidya Sagar Reddy, "Quality changes in fish burger from Catla (Catla Catla) during refrigerated storage," Journal of Food Science and Technology, vol. 52, no. 3, pp. 1766-1771, 2015.

[42] M. Dammak, B. Hadrich, R. Miladi et al., "Effects of nutritional conditions on growth and biochemical composition of Tetraselmis sp.," Lipids in Health and Disease, vol. 16, no. 1, article no. 41, 2017.

[43] T. Wang, R. Jónsdóttir, H. G. Kristinsson et al., "Inhibition of haemoglobin-mediated lipid oxidation in washed cod muscle and cod protein isolates by Fucus vesiculosus extract and fractions," Food Chemistry, vol. 123, no. 2, pp. 321-330, 2010.

[44] S. Roohinejad, M. Koubaa, F. J. Barba, S. Saljoughian, M. Amid, and R. Greiner, "Application of seaweeds to develop new food products with enhanced shelf-life, quality and health-related beneficial properties," Food Research International, vol. 99, pp. 1066-1083, 2017.

[45] P. B. Andrade, M. Barbosa, R. P. Matos et al., "Valuable compounds in macroalgae extracts," Food Chemistry, vol. 138, no. 2-3, pp. 1819-1828, 2013.

[46] A. López, M. Rico, A. Rivero, and M. Suárez de Tangil, “The effects of solvents on the phenolic contents and antioxidant activity of Stypocaulon scoparium algae extracts," Food Chemistry, vol. 125, no. 3, pp. 1104-1109, 2011.

[47] I. López-López, S. Cofrades, and F. Jiménez-Colmenero, "Lowfat frankfurters enriched with n-3 PUFA and edible seaweed: Effects of olive oil and chilled storage on physicochemical, sensory and microbial characteristics," Meat Science, vol. 83, no. 1, pp. 148-154, 2009.

[48] I. López-López, S. Cofrades, V. Cañeque, M. T. Díaz, O. López, and F. Jiménez-Colmenero, "Effect of cooking on the chemical composition of low-salt, low-fat Wakame/olive oil added beef patties with special reference to fatty acid content," Meat Science, vol. 89, no. 1, pp. 27-34, 2011.

[49] T. Backers and B. Noll, "Dietary fibers move into meat processing," Fleischwirtschaft-Frankfurt, vol. 78, p. 316, 319-320, 344, 1998.

[50] F. Jiménez-Colmenero, S. Cofrades, I. López-López, C. RuizCapillas, T. Pintado, and M. T. Solas, "Technological and sensory characteristics of reduced/low-fat, low-salt frankfurters as affected by the addition of konjac and seaweed," Meat Science, vol. 84, no. 3, pp. 356-363, 2010.

[51] A. Senthil, B. S. Mamatha, and M. Mahadevaswamy, "Effect of using seaweed (eucheuma) powder on the quality of fish cutlet," International Journal of Food Sciences and Nutrition, vol. 56, no. 5, pp. 327-335, 2005.

[52] H.-W. Kim, J.-H. Choi, Y.-S. Choi et al., "Effects of sea tangle (Lamina japonica) Powder on quality characteristics of breakfast sausages," Korean Journal for Food Science of Animal Resources, vol. 30, no. 1, pp. 55-61, 2010. 


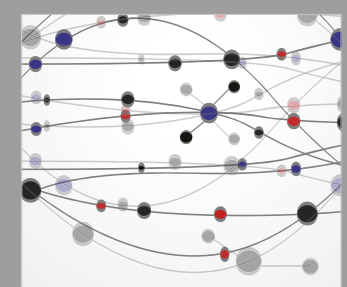

The Scientific World Journal
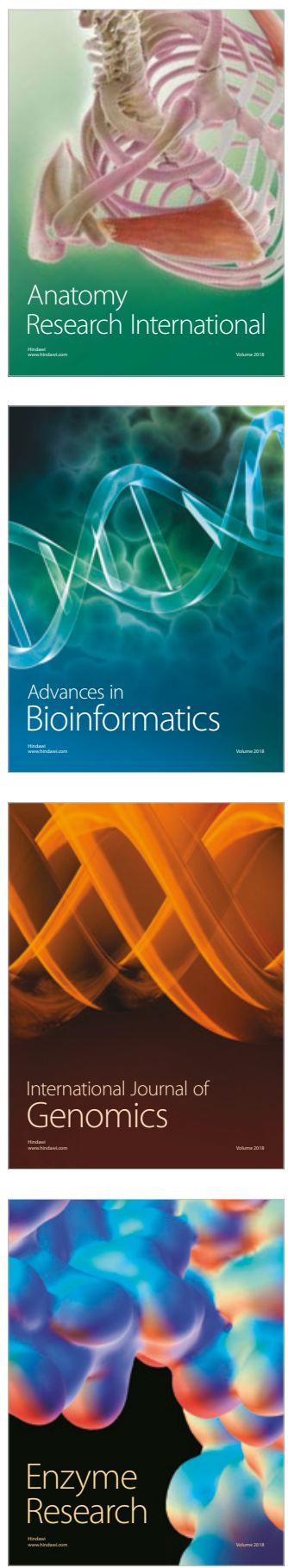
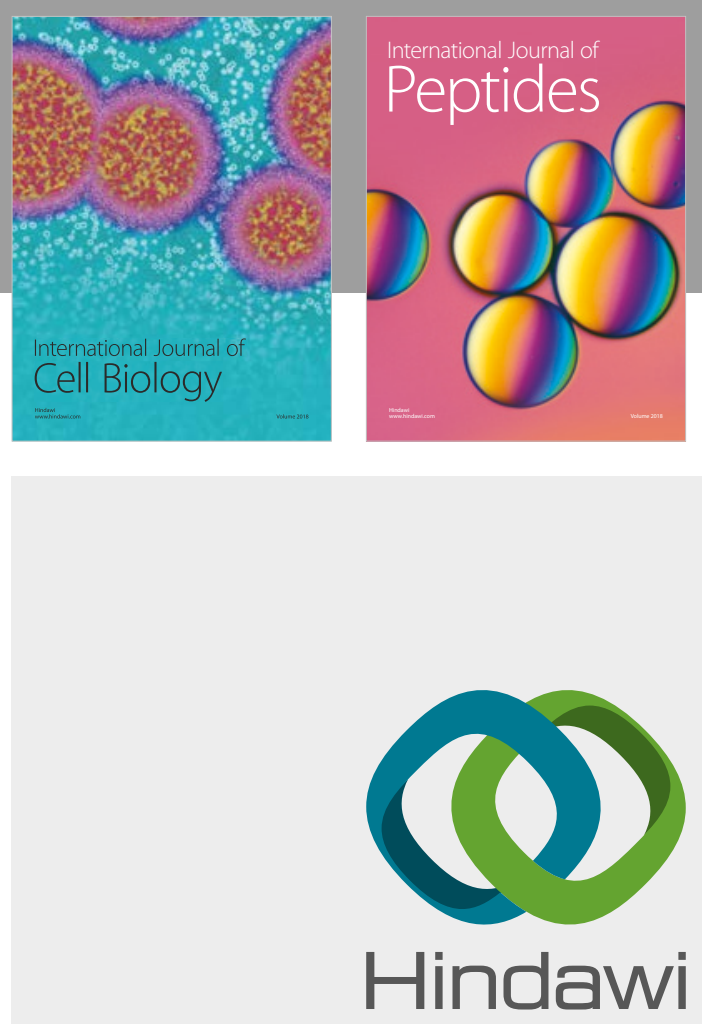

Submit your manuscripts at

www.hindawi.com
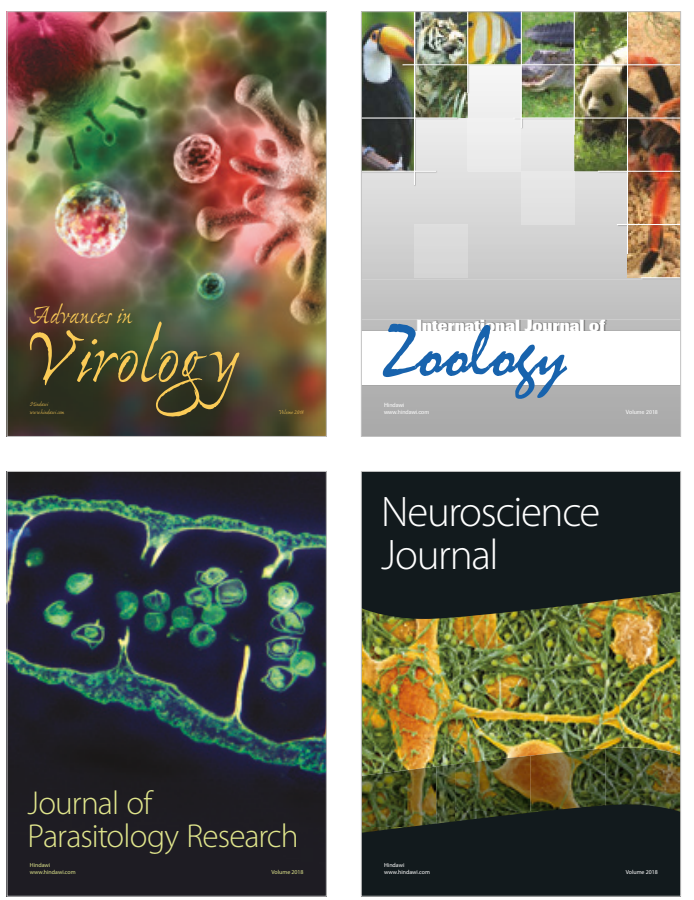
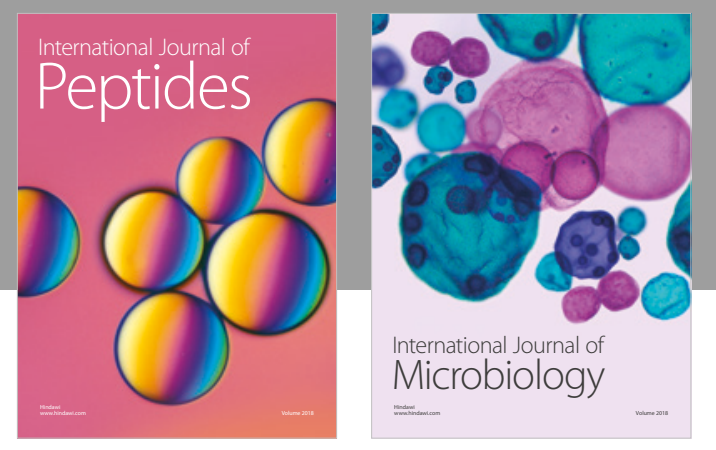

nternational Journal of Microbiology
Journal of
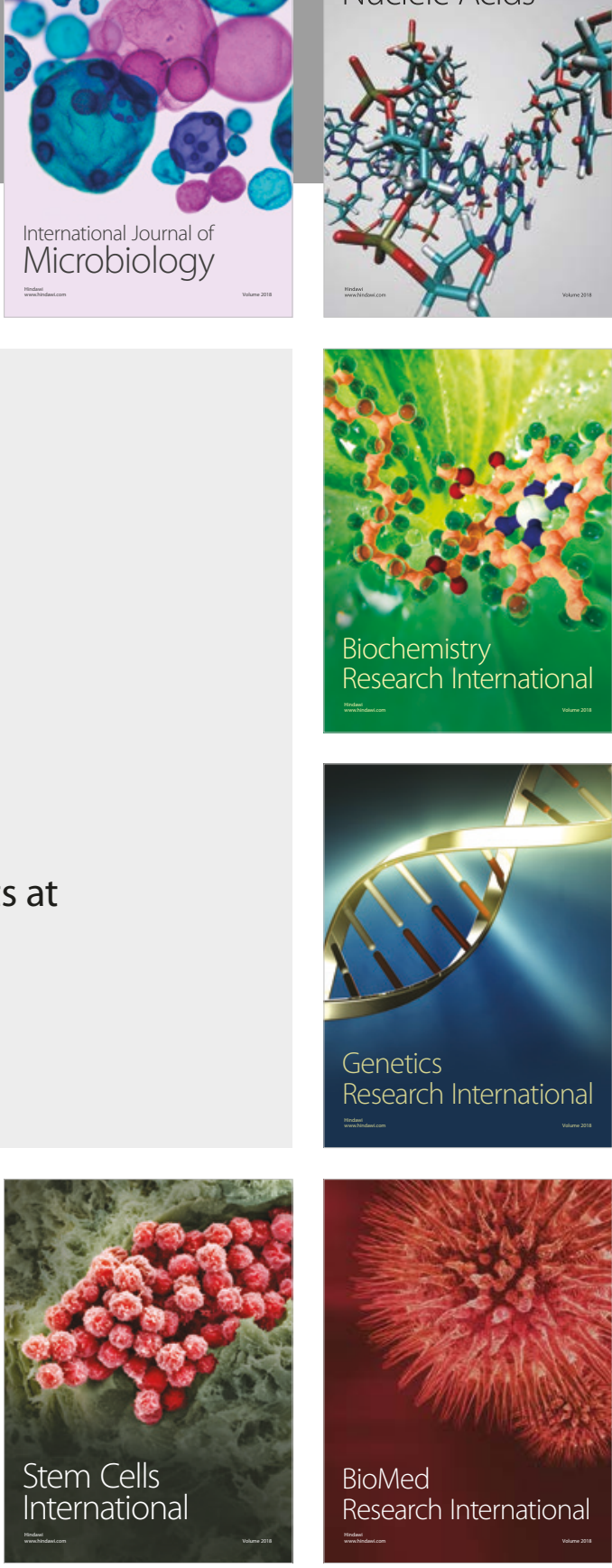
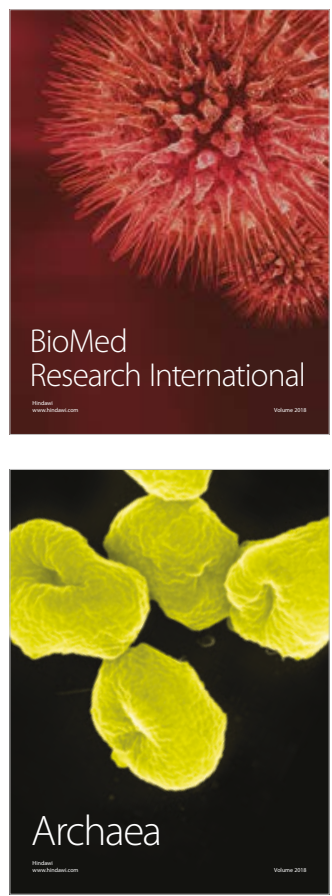